\title{
Analysis of methods for high-speed forming the relief microimages on metallic substrates
}

\author{
A.A. Kryuchyn, A.V. Pankratova, I.A. Kassko, A.V. Nagorny, D.V. Chirkov \\ Institute for Information Recording, NAS of Ukraine \\ 2, Shpak str., 03113Kyiv, Ukraine \\ E-mail: kryuchin@ipri,kiev.ua \\ Phone +380(044)454-2152; fax +380(044)241-7233
}

\begin{abstract}
The use of methods of ion and electrochemical etching of metallic substrates to obtain relief microstructures with micron and submicron sizes is considered. Presented are the results of experimental researches of processes aimed at manufacturing metallic carriers by using inorganic photoresists.
\end{abstract}

Keywords: nickel stamper, metallic carrier, optical read-out, data storage, compact disk, electroforming, chalcogenide glass.

Manuscript received 14.11.07; accepted for publication 19.12.07; published online 11.02.08.

\section{Introduction}

One of the main directions of developing technology for $\mathrm{CD}$ making is improvement of the process of manufacturing metallic stampers for $\mathrm{CD}$ replication. Considerable attention is paid to simplification of the stamper-making process and its reduction. The technological process aimed at making nickel stampers by standard technology of photoresist mastering includes performance of 13 operations. It requires considerable capital investments for the purchase of technological equipment and considerable charges for training skilled specialists for performing each of technological operations. In the technological process of making the stampers for $\mathrm{CD}$ replication, the most protracted operation is the electrochemical plating of nickel stampers. In addition, this operation is the most ecologically dangerous, and this circumstance does not allow a considerable part of CD replicators to organize their own mastering. By some estimations, the amount of companies without own mastering reaches almost $50 \%$ of the general amount of CD replicators [1]. Absence of own mastering substantially increases time for performing the orders for $\mathrm{CD}$ making. It is necessary to note that the cost of making CDs of all types diminishes constantly, while the cost of making the stampers remains almost unchanged. In recent $4-5$ years, time of stamper making was slightly shortened, in the first place, due to reduction of time for information recording on master disks (widely used is $4 \times$ and $8 \times$ multiple speed of information recording -600 and $1200 \mathrm{Kbyte} / \mathrm{s}$ ), and as well as to reception of information with high speeds over computer networks [2]. The process of electroforming, however, did not undergo considerable changes and more and more begins to retard the process of mastering (plating the stamper and its tooling last approximately for an hour). A base engineering solution consists in using in the process of mastering nickel substrates preliminary made by the method of electroforming. Deposited on these substrates are the following photosensitive materials: negative or positive organic photoresists (the type of photoresist is chosen in the dependence on the selected method to form relief microstructures on a metallic substrate) [3-5], easily sublimating films of organic dyes [6], inorganic photoresists [5,7]. One of additional advantages of nickel substrates is decrease of photoresist overheat during the high-speed information recording on a master disk [5].

Technologies of the rapid making of microrelief structures on metallic substrates are needed both for acceleration of the process for CD making, diffraction optical elements, holographic protective elements, and carriers for long-term data storage. Technology of direct mastering foresees the obligatory use of nickel substrates in master carriers, and the manufactured stamper must present a nickel plate with a microrelief structure on its surface, made from materials which have high mechanical strength. 


\section{Analysis of development and improvement trends for methods of making stampers for $C D$ replication}

In view of the change-over to making optical disks of new generations $\mathrm{HD}, \mathrm{DVD}, \mathrm{BD}$ (Blu-ray disc) the requirements to stampers grow considerably. It is necessary to provide the forming on the surface of a relief microstructure with minimal sizes of 0.15 to $0.2 \mu \mathrm{m}$, deviations from which should not exceed $10 \%$ of optimum values. The requirements to the flatness of stampers and allowable deviation from a predetermined thickness (no more than one micrometer) rise essentially. One of the ways to provide requirements to stamper characterictics is the use of substrates of stampers preliminary made on the specialized enterprises both from nickel and silicon or silicon carbide. The use of the specially prepared substrates also allows to increase the speed of performing the process of mastering.

In most of the used systems for direct (high-speed) mastering on the surface of a nickel substrate, a relief microstructure which is used for plastic $\mathrm{CD}$ replication is formed of material of a photosensitive layer [3]. The increase of mechanical strength of relief microstructure on the surface of a nickel substrate is achieved by annealing at the elevated temperature of photoresist residues by using ultraviolet irradiation $[1,8,9]$. To increase the amount of high-quality imprints, which can be obtained from a stamper, one can reach by using additional metallization of a relief microstructure [3] as well as using nickel substrates made by electrochemical plating and including as a component up to $15 \mathrm{wt} \%$ of phosphorus [10]. Other way lies in the fact that, on the surface of a nickel substrate before deposition of a photoresist layer, one apply a primer coating with material of which a microrelief photoresist structure formed after recording and selective chemical treatment forms a rather mechanically stable structure at the following high temperature treatment. The developers of such direct mastering technology consider that the amount of the made CDs with the use of such a stamper can be increased almost by an order in comparison with stampers made by direct mastering technology with annealing of photoresist residues [1]. The direction of using photoresists with substantially higher mechanical strength is promising. Such properties are observed in non-organic photoresists based on chalcogenide semiconductors [7]. To provide high light-sensitivity and selectivity of etching, on the one hand, and the considerable mechanical strength, on the other hand, is possible only using multilayer inorganic photoresists in which the change of solubility under the action of light is related with photostructural transformations. It complicates the process of their making and application considerably. In recent years, considerable attention is paid to developments of inorganic photoresists in which under the action of focused laser radiation phase transitions of the type "crystal - glass" are observed. Since the changes of chemical properties take place only in areas, the temperature on boundaries of which equals to the temperature of phase transition, and the information recording is carried out by a beam with the Gaussian intensity distribution, there is the possibility to diminish the size of written elements in comparison with the diameter of a focused laser beam [5].

Materials used in these inorganic resists are similar to the chalcogenide semiconductors on which the data recording is carried out when using CD-RW (DVDRW). Information recording on these materials is carried out at the density of laser radiation of tens of megawatts $/ \mathrm{cm}^{2}$, and it can result in local destruction of the photoresist layer. In CDs, this problem is solved by locating a photoactive layer between sealing layers made from high-temperature materials. To prevent local destruction of the photoresist layer, it is offered its deposition on substrates with a higher thermal conductivity [11].

According to physical properties (strength, hardness) most close to the standard stampers, obtained by methods of electroforming are, stampers, made from nickel substrates by using processes of selective etching of nickel $[8,12]$ or plating of nickel in windows which are formed in a photosensitive layer. To realize the process of selective plating, negative photoresists are used, and at introduction of technology of selective etching of nickel substrates, positive photoresists are used. Creation of relief microimages in a protective layer on the surface of a nickel substrate, through which selective etching of nickel or its plating is carried out, can be performed by technology of using photoresists or local evaporation of a light-absorbing layer. A main problem during realization of processes of selective etching (plating) of nickel in windows in the photosensitive layer is in the incomplete withdrawal of the photosensitive layer material from pits. Especially problematic is the use in this process of photosensitive materials with the ablative method of recording at which a part of material of a photosensitive layer remains in pits as drops. It is necessary to develop and use special operations for preparing the surface (its cleaning) at the bottom of pits.

In the first works on creation of direct mastering technology, the processes of local evaporation of metal on the metallic (nickel) substrates were offered and studied $[10,12]$. Owing to high thermal conductivity of metallic substrate the ablative method of recording cannot provide making the stampers with characteristics inherent to stampers made using traditional technology of photoresist mastering. Technology of ablative direct mastering does not allow to make stampers for replication of DVD-carriers and CDs of next generations (Blu-ray disc, HD-DVD).

Attention of researches is now attracted to the methods of making stampers in which a relief microstructure is formed in the layers deposited on the metallic substrate with high mechanical resistance.

Also known is method that allows to obtain a relief image on the surface of a substrate of master disk, which lies in the fact that the surface of a master disk substrate is sequentially covered by a conductive layer of titanium 
nitride, a layer of radiation-sensitive material; then one expose this layer to radiation; withdraws it in the exposed areas and withdraws parts of the titanium nitride layer. The information recording on the master disk can be carried out by actinic laser radiation or electron flow.

The highest precision in the process of selective etching of a nickel substrate can be provided by the methods of ion etching [10]. On the whole, the firmsdevelopers of the direct mastering systems prefer to use dry methods of substrate treatment [8]. It is thus succeeded to solve a problem of the withdrawal of contaminations from pits and obtain pits with the minimum roughness of walls, which improves quality of reproduction of written information considerably.

The performed analysis showed that processes of inorganic photolitography and ion etching of nickel substrates are to be considered as the most promising directions in direct mastering technologies.

\section{Research of the process for ion-plasma etching the nickel substrates with a protective photoresist layer}

For a long time in technology of CD making, the methods of ion treatment were used exceptionally for cleaning the surface of nickel stamper from photoresist residues. The first researches of the process of ion etching of nickel substrate were executed at the Massachusetts Technological Institute (USA), and they showed possibility to make nickel stampers by ion etching the nickel substrates through windows in a negative photoresist [14]. The advantages of such a method of treatment consist in a possibility to reduce the time for making stampers for $\mathrm{CD}$ replication and providing high surface finish of stampers. For wide using this technology of making stampers, it is necessary to provide high selectivity of the process of ion etching (for preventing substantial increase of photoresist layer thickness, which results in limitations at high-density information recording). The process of ion etching allows to make stampers from different materials includihg silicon and silicon carbide [14].

Nickel stampers made by the method of ion-plasma etching the substrates of nickel by their basic characteristics conform to indexes of stampers obtained by electroforming methods, but excel them in surface finish. The photoresist residues cause the appearance of microdefects on the stamper surface. These residues is offered to withdraw by treatment in plasma of oxygen (this process is the most effective, but protracted enough and requires the presence of an additional vacuum equipment) or by elemental oxygen formed during irradiation of stampers by ultraviolet radiation.

The treatment of metallic (nickel) master disks was carried out using VU-1A vacuum unit, in which the ion source Ion-2 was installed. The distance between the cathode of the ion source and the master disk surface was $200 \mathrm{~mm}$. Selective etching of the nickel substrate was carried out through windows in the negative photoresist layer at the argon pressure of $0.02 \mathrm{~Pa}$ (working chamber was preliminary pumped out to $0.001 \mathrm{~Pa})$. The treatment of the metallic master disk surface was carried out by accelerated argon ions $(U=$ $1000 \mathrm{~V})$. In the process of treatment of a $160-\mathrm{mm}$ diameter nickel disk, the ion current was $200 \mathrm{~mA}$ and time of treatment was $10-12 \mathrm{~min}$. The time of treatment by accelerated argon ions and photoresist thickness were chosen in such a way that, after the withdrawal of photoresist, the height of bumps was $(150 \pm 2) \mathrm{nm}$. The process of ion etching was stopped when reaching mirror reflection from the surface of a metallic master disk. The continuation of the etching process (for 3-5 minutes) after the withdrawal of photoresist residues did not cause the change of the bump shape on the master-disk surface, but contributed to the complete withdrawal of photoresist residues from the surface of a nickel stamper. It was established by an experimental way that bumps on the surface of the nickel stamper with the height necessary for $\mathrm{CD}$ stamping at the standard mode of photoresist annealing after selective etching (time of annealing at the temperature of $90{ }^{\circ} \mathrm{C}$ is $20 \mathrm{~min}$ ) can be obtained by using $120-\mathrm{nm}$ thick photoresist. The stampers, bumps on which were obtained by the method of ion etching, had a homogeneous surface with a high coefficient of optical radiation reflection; it was not revealed residues of photoresist, contaminations by organic matters, which considerably worsen the quality of imprints in the process of replication, on the surface of stampers ready for service.

A main problem in realization of this method to make stampers is in making nickel substrates with the minimum butt-end run-out. The high surface finish of a nickel substrate is provided by careful preparation of the surface of a master carrier, on which a nickel substrate is plated.

\section{Analysis and research of methods aimed at making stampers by using single crystals}

In connection with the increase of requirements to stampers, which is planned to be used in the next generation $\mathrm{CD}$ replication, stampers made from monocrystalline materials (such as silicon carbide, silicon, etc.) draw attention of researchers. The choice of these materials is connected with the complex of their physical and chemical properties: high homogeneity and surface finish of single crystals, strength, absence of impurities, possibility of obtaining mirror surfaces when tooling.

The wide use of substrates of monocrystalline materials in microelectronics favours manufacturing stampers of these materials, too. Substrates of silicon, the diameter of which already reaches $300 \mathrm{~mm}$, are most widely used. The use of such substrates in solar elements favours this. Recently, considerable progress has been achieved in technology of making substrates of $\mathrm{SiC}$, AlN, GaN. Characteristics of substrates made of these materials are given in Table 1 [16].

\section{(C) 2007, V. Lashkaryov Institute of Semiconductor Physics, National Academy of Sciences of Ukraine}


Table 1. Characteristics of some monoctystalline substrates.

\begin{tabular}{|c|c|c|c|}
\hline $\begin{array}{c}\text { Substrate } \\
\text { material }\end{array}$ & $\begin{array}{c}\text { Diameter, } \\
\mathrm{mm}\end{array}$ & $\begin{array}{c}\text { Density } \\
\text { of defects, } \\
\text { defect/cm }\end{array}$ & $\begin{array}{c}\text { Electric } \\
\text { resistance, } \\
\text { Ohm/cm }\end{array}$ \\
\hline $\mathrm{SiC}$ & 75 & $<5 \cdot 10^{-6}$ & $>10^{11}$ \\
$\mathrm{GaN}$ & 15 & $<10^{5}$ & $>10^{9}$ \\
$\mathrm{AlN}$ & 25 & $<10^{4}$ & $>10^{12}$ \\
\hline
\end{tabular}

For making master disks and stampers, the use of monocrystalline silicon disks is offered. It is connected with availability and manufacturability of making silicon single crystals of necessary sizes and disk polished substrates of necessary sizes (diameter is $160 \mathrm{~mm}$, thickness is 1.5 to $3 \mathrm{~mm}$ ). In addition, thermophysical properties of silicon substrates allow to carry out information recording on master disks made from them with high speed recording without local photothermal destruction of a photoresist layer (it concerns both organic and inorganic photoresists). The conducted experimental researches demonstrated the possibility of obtaining on master disks with silicon substrates the recording density of $104 \mathrm{~Gb} / \mathrm{inch}^{2}$ (that provides a 120 $\mathrm{mm}$ diameter disk capacity of 150 Gbyte). Such high values of recording density, which confirm expedience of using monocrystalline silicon substrates in superdense mastering systems, were obtained by using electronbeam exposure. Selective etching of a substrates through windows in a photoresist layer was carried out by the plasmochemical method (working gas is $\mathrm{CF}_{4}$ ). The withdrawal of photoresist residues was carried out by etching in oxygen plasma. The reproduction of information, presented as a microrelief structure, was carried out by using a solid-state immersion optical system with the numerical aperture $\mathrm{NA}=2.05$.

Two variants of using monocrystalline silicon substrates were analyzed and studied by us: making stampers for $\mathrm{CD}$ replication based on single-crystal silicon and using the monocrystalline silicon substrates with a different degree of doping in the mastering process (in master-carriers). The change of silicate glass substrates to silicon substrates allows to improve the quality of stampers due to a higher surfaces finish of substrates, besides, it allows to carry out the data recording with a higher speed. The change of substrate material in the mastering process need not any changes in the technological process of CD replication.

More substantial influence on the mastering process can be observed when using the monocrystalline silicon stampers.

The process of forming the relief microstructures was investigated by us on the surface of monocrystalline silicon substrates by using Shipley 1805 positive photoresist, exposure of which was carried out by optical radiation with $405 \mathrm{~mm}$ wavelength. Etching of silicon was carried out in plasma of $\mathrm{CF}_{4}$. A difference in speeds of photoresist and silicon etching was 4 times, which allowed to obtain recesses of $600 \mathrm{~nm}$ depth at the thickness of photoresist $150 \mathrm{~nm}$. It creates a possibility of using these substrates for making stampers for CD-R replication.

Presented in Fig. 1 is a microrelief structure obtained on silicon by plasmochemical etching (an image is obtained using a tunnel scanning microscope).

The geometrical sizes of recesses, inclination of walls, conform to standard sizes of pits on CDs. It enables to examine the process of formation of microrelief structures on silicon as promising for creating master disks and stampers of silicon.
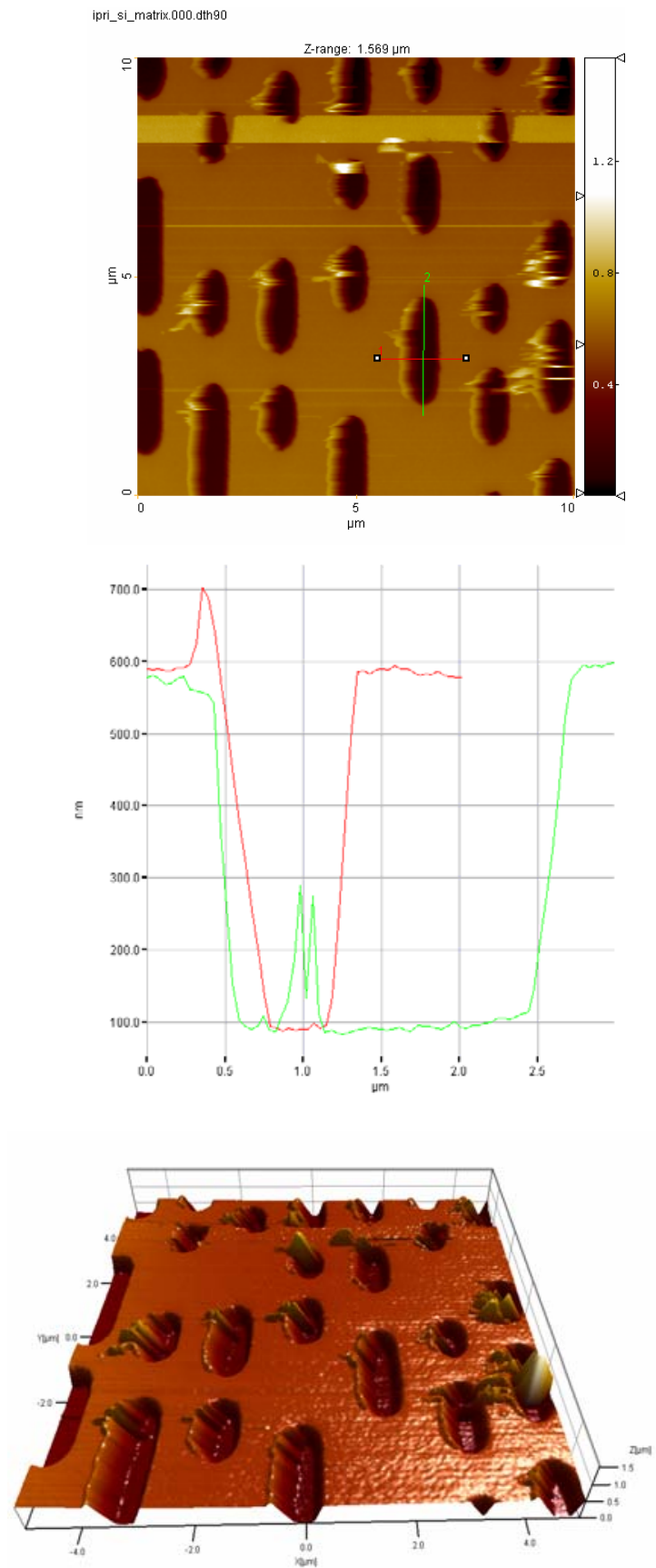

Fig. 1. Microrelief structure, obtained on a silicon substrate by plasmochemical etching: A - top view of a substrate, B cross-section of pits, $\mathrm{C}-$ three-dimensional image of a surface.

\section{(C) 2007, V. Lashkaryov Institute of Semiconductor Physics, National Academy of Sciences of Ukraine}


To determine boundary values of the recording density, master disks of monocrystalline silicon were used. Recording the directed tracks was performed using the electron-beam mastering station, whereupon nickel stampers were made by the method of electroforming. Then they were used for molding substrates of disks with a capacity of 43 Gbyte (recording density is 31.0 Gbit/inch ${ }^{2}$ ) [16].

The improved constructions of injection molding machines for new-generation CD molding, in which a stamper is located on a stationary part, are suitable to use stampers of monocrystalline materials [17].

The use of monocrystalline silicon substrates also allows to improve the process of making the nickel stampers.

A method of making a master-disk of single crystal silicon was offered by us. It is based on deposition of radiation-sensitive layer on substrates, irradiation of a layer by modulated actinic radiation, the withdrawal of it in exposed areas, and through a protective layer of radiation-sensitive material the withdrawal of a part of a silicon conducting layer.

Making a master disk substrate of single crystal silicon will allow to improve the quality of making a master disk owing to high quality of the monocrystalline silicon surface. The main thing lies in the fact that sufficiently high conductivity of doped silicon allows to plate a nickel layer directly on its surface without application of metallization of relief image on the master-disk surface or of an additional layer with a low electric resistance.

The silicon substrate has the thickness $1.5-3.0 \mathrm{~mm}$, which provides high mechanical strength of a master-disk. The shelf-life of a master-disk as a silicon substrate with relief image is practically unlimited in time. The metal of a stamper (nickel) can be plated on the surface of a master disk multiply, what eliminates the necessity of making intermediate copies. A current in the process of plating stamper in an initial period can be increased 5-10 times. It allows to shorten the time of making the stampers.

\section{Analysis of processes of nickel plating in photoresist windows}

Nickel stampers have a lot of advantages above other stampers, an information layer of which is made from organic and inorganic dielectric materials. Their main advantage consists in high reliability in the process of the use and long-term shelf-life. Therefore, considerable attention is paid to creation of technology of the high speed making the continuous metallic stampers. The process of their making is also based on the use of preliminary prepared nickel substrates, deposited on which are layers of positive or negative photoresist, when information recording is carried out by focused laser radiation by using the laser-beam recorder. After selective etching of a positive resist, its annealing, on the nickel substrate surface a microrelief structure is formed with pits (recesses), the depth of which equals to the necessary height of bumps on a stamper (for stampers used in CD production it is $150 \mathrm{~nm}$; and for stampers in DVD production - it is $120 \mathrm{~nm}$ ). To obtaine a highquality stamper, the angle of inclination of pit walls must be $(60-70)^{\circ}$, and there must be no photoresist residues at the pit bottom. It is necessary to note that signal amplitude of reproduction from CDs is in the straight proportion to the volume of pits on their surface. Researches performed by us showed that by using Shipley 1805 (1813) positive photoresist, exposure of which is carried out by actinic radiation, focused to $0.7 \mu \mathrm{m}$ (by the level $1 / \mathrm{e})$, one can obtain pits with almost vertical slopes and absence of photoresist residues inside a pit.

This feature of etching photoresist layers enables to realize the technological process of direct mastering with plating of metal in photoresist windows. The formation of pits of a predetermined shape is possible subject to focusing laser radiation within the accuracy not worse than $\lambda / 10$ and obtaining rigorously predetermined diffraction efficiency of a beam, reflected from a set of information tracks.

The attained speeds of nickel plating in the process of plating nickel stampers of 5 to $8 \mu \mathrm{m} / \mathrm{min}$ is too high for providing homogeneous plating of nickel. It is necessary to diminish considerably the voltage, at which the process of electroforming is executed. Plating the nickel precipitates by using low voltage $(0.1-0.5) \mathrm{V}$ from sulfamat solutions results in enriching the precipitate by impurities containing in the electrolyte. To diminish the speed of nickel plating, we placed special shields and increased the distance between an anode and cathode. Presented in Fig. 2 are three-dimensional images of nickel bumps on a metallic substrate, which give an evidence of possibility to obtain nickel stampers by plating a stamper into photoresist windows. The conducted analysis of composition of nickel bumps showed that it almost coincided with composition of nickel substrates plated in the same bath (Table 2).

The certification of stamper chemical composition was conducted by VG9000 mass-spectrometer with excitation of the secondary ions by a glow discharge.

A higher amount of impurities in the plated bumps can be connected with carrying-out the process of nickel plating at low voltages and low currents. The obtained purity of precipitates allows to forecast making stampers which provide CD replication up to tens of thousands copies.

Table 2. Composition of substrate and bumps on a nickel stamper.

\begin{tabular}{|c|c|c|}
\hline $\begin{array}{c}\text { Chemical } \\
\text { element }\end{array}$ & $\begin{array}{c}\text { Nickel substrate } \\
\text { (stamper), mass \% }\end{array}$ & $\begin{array}{c}\text { Nickel bumps, } \\
\text { mass \% }\end{array}$ \\
\hline $\mathrm{Ni}$ & 97.78 & 97.02 \\
$\mathrm{Al}$ & 0.66 & 0.76 \\
$\mathrm{Si}$ & 0.58 & 0.64 \\
$\mathrm{O}$ & 0.7 & 0.78 \\
$\mathrm{Mo}$ & 0.08 & 0.12 \\
$\mathrm{Fe}$ & 0.08 & 0.26 \\
$\mathrm{Zn}$ & 0.05 & 0.23 \\
$\mathrm{Pl}$ & 0.07 & 0.19 \\
\hline
\end{tabular}




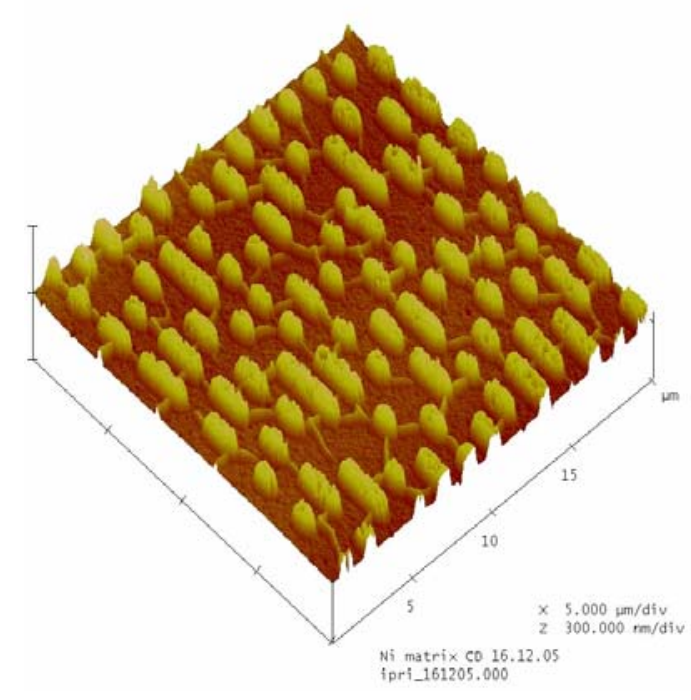

Fig. 2. Three-dimensional image of nickel bumps on a metallic substrate.

When plating bumps on a nickel substrate, it is necessary to solve a task which consists in obtaining a reliable joint between a substrate and a plating layer, that is why it is necessary to develop a special technology of treatment of substrate surface before nickel plating. It must be chemical or electrochemical etching in solutions of acids or salts. Electrochemical etching also allows to withdraw photoresist residues and other technological contaminations.

Electrochemical etching was performed in the same plating bath, in which the process of nickel plating is carried out, at the change of polarity of power voltage. Thus, a stable oxide film is broken down, and a continuous metallic stamper is formed after nickel plating on the activated surface.

Except for the electrochemical method, continuous metallic stampers were made by the method of the chemical deposition of nickel from water solutions with subsequent chemical treatment of precipitates. The precipitate is mostly a binary and ternary alloy of Ni-P, $\mathrm{Ni}-\mathrm{B}, \mathrm{Ni}-\mathrm{Co}-\mathrm{P}$ et al. with low porosity.

The plating of bumps was executed by traditional technology of plating metal on a dielectric, including the stages of activation and sensitization of a surface. Before plating electrochemical treatment was also performed in solution that is used for electrocleaning aimed at withdrawal of a stable oxide film.

\section{Conclusions}

The performed analysis of modern technologies of making stampers for $\mathrm{CD}$ replication, holographic protective elements, diffraction grating and executed experimental researches on the improved process of CD mastering showed that to improve the quality of master disks and stampers for $\mathrm{CD}$ replication, to shorten time of making stampers is possible owing to the use of new materials for substrates of master disks, inorganic photoresist and photosensitive organo-metallic compositions. The use in the process of CD mastering of 300$\mu \mathrm{m}$ thick nickel substrates is possible only at substantial extending the dynamic range of the automatic laser radiation focusing system and increasing speed of a microobjective movement mechanism of the laser radiation focusing system. Expedience of using piezoelectric elements in fast-acting high-precision systems of the automatic laser radiation focusing is shown. The made researches showed that the use of the monocrystalline substrates for master disks can improve the quality of stampers for CD replication, shorten time of making stampers owing to the withdrawal of the operation of master-disk metallization from the technological process and using special monocrystalline stampers.

\section{References}

1. K. Sano, H. Miyakita, Development of direct mastering system // Jpn J. Appl. Phys. 42(1), p. 7140-7146 (2003).

2. C.A. Snape, Mastering for the future at Xonen technologies // One to One No. 1, p. 44-48 (2003).

3. C.A. Snape, CD: still generating business for ingrowth mastering equipment // One to One No. 6, p. 47-54 (2003).

4. Japan Patent JP 2001283475. MPK ${ }^{6}$ G11 B 7/26. Direct mastering substrate and its manufacturing method / S. Kazuhiko, Matsushita Electric Ind. Co. Ltd (Japan). Appl. 12.10.2001. Publ. 20.12.2003.

5. Kashiwagi, PTM: an alternative solution to mastering blue-ray disc // One to One No. 8, p. 57-60 (2004).

6. www.obducat.com.

7. S.A. Kostyukevych, P.Ye. Shepeliavyi, N.L. Moskalenko et al., Investigation of the process of mastering the compact-disks by using non-organic photoresists // Reyestratsiya, zberigannya ta obrobka danykh 3(4), p. 5-11 (2001) (in Ukrainian).

8. Japan Patent JP 2001143333. MPK G11 B 7/26. Method for direct dry mastering of stamper for an optical disk and apparatus therefore / S. Kazuhiko, Matsushita Electric Ind. Co Ltd (Japan). Appl. 25.05.2001. Publ. 16.06.2003.

9. USA Patent № 6423477. MPK ${ }^{6}$ G11 B 7/26. Method of manufacturing a stamper for producing optical discs, a stamper thus obtained and an optical disc obtained by using such stamper / T.W. Engelen, T.M. Walter et al. (Netherland), ODME Int. B.V. (Netherland). Appl. 7.10.98. № 09/529011. Publ. 23.07.02.

10. USA Patent № 5783371. $M P K^{6}$ G11 B 7/26. Process for manufacturing optical data storage disk stamper / T.G. Bifano, Boston University (USA). Appl. 1.04.1996. № 625820. Publ. 21.07.1998. 
11. E. Toppin, Mastering the challenges of high definition formats // One to One No. 6, p. 22-28 (2005).

12. Japan Patent JP 2001216690. MPK G11 B 7/26. Direct mastering method and device for the same / S. Kazuhiko, Electric Ind Co Ltd (Japan). Appl. 10.08.2001. Publ. 12.09.2003.

13. V.V. Petrov, A.A. Kryuchin, A.P. Tokar', S.M. Shanoilo, V.Ya. Sandul, Optic-and-mechanical storage facilities. Naukova Dumka, Kyiv, 1992.
14. T.G. Bifano, H.E. Fawcett, P.A. Bierden, Precision manufacture of optical disc master stampers // Precision Engineers 20(1), p. 54-62 (January 1997).

15. G. Purvis, Wide bandgap and MMICs // III-Vs Review (The Advanced Semiconductor Magazine) 18, No. 4, p. 24-25 (2005).

16. M. Shinoda, K. Saito, T. Ishimoto, et al., High density near-field optical disc recording using phase change media and polycarbonate substrate // Proc. SPIE 5380, p. 225-227 (2004).

17. P. Sundberg, Moulding solutions for stringent requirements // The Next Generation (One to One special report) p. 32-33 (2005). 